\title{
Direitos humanos e trabalho infantil na Amazônia: a lógica do capital predatório e a subversão de crianças no norte do Brasil
}

\author{
Derechos humanos y trabajo infantil en la \\ Amazonia: la lógica del capital depredatorio y \\ subversión de la infancia en el norte de Brasil
}

\section{Human rights and child labor in the Amazon: the logic of predatory capital and child subversion in} northern Brazil

\author{
Simei Santos Andrade \\ ORCID ID: 0000-0002-7281-3946 \\ Universidade Federal do Pará (UFPA), Brasil \\ Raquel Amorim dos Santos \\ ORCID ID: 0000-0003-4817-0036 \\ Universidade Federal do Pará (UFPA), Brasil \\ Autor referente: simeiandrade@ufpa.br \\ Historia editorial \\ Recibido: 11/01/2021 \\ Aceptado: 09/04/2021
}

\section{RESUMO}

O estudo tem por objetivo analisar a lógica do capital predatório para com o grupo geracional infância, e como as crianças ribeirinhas, indígenas, caboclas, quilombolas, pescadoras, praieiras, camponesas, povos da floresta, sem-terra, assentadas, pequenas agricultoras, imigrantes, colonas e urbanas subvertem essa lógica capitalista. A metodologia aplicada se deu por meio de uma

abordagem qualitativa, baseada numa pesquisa bibliográfica e documental. A base de dados que fomentou o estudo centrou-se em organizações governamentais e não governamentais com destaque para UNICEF, IMAZON, IBGE, OIT, Agência Brasil, Ministério da Mulher, da Família e dos Direitos Humanos, Ministério da Educação, Ministério da Justiça/Polícia Rodoviária Federal, Secretaria Especial de 
Previdência e Trabalho, com foco na Amazônia paraense. Os principais resultados mostram que o atendimento às necessidades básicas das crianças e as políticas de proteção e seguridade social para 0 seu pleno desenvolvimento ainda são um grande abismo entre o que o Estado, por meio das políticas públicas e da legislação diz, e o que as crianças vivem de fato nos diversos espaços geográficos da
Amazônia. As conclusões do estudo mostram que as crianças, mesmo com a exploração de sua mão de obra que rouba seus direitos a uma vida digna, a brincar, a ir à escola, à educação, à saúde e à habitação de qualidade, ainda assim subvertem a lógica capitalista e por meio de suas culturas infantis lutam e resistem à barbárie do mundo "civilizado".

Palavras-chave: Direitos humanos; trabalho Infantil; Infâncias Amazônicas; Amazônia Paraense.

\section{RESUMEN}

El objetivo de este estudio es analizar la lógica del capital depredador para un grupo generacional de niños, como ribereños, indígenas, caboclas, quilombolas, pescadores, trabajadores de la playa, campesinos, pueblos del bosque, sin tierra, colonos, pequeños agricultores, inmigrantes, colonos. y subversión urbana esta lógica capitalista. La metodología aplicada se derivó de un enfoque cualitativo, basado en la investigación bibliográfica y documental. Basado en datos que promueven o estudian la centralidad de las organizaciones gubernamentales y no gubernamentales, en particular UNICEF, IMAZON, IBGE, OIT, Agência Brasil, Ministerio de la Mujer, Familia y Derechos Humanos, Ministerio de Educación, Ministerio de Justicia / Policía Federal de Carreteras, Secretaría Especial de Seguridad
Social y Trabajo, con enfoque en la Amazonia en Paraguay. Los principales resultados muestran que la satisfacción de las necesidades básicas de la niñez y las políticas de protección y seguridad social para su pleno desarrollo aunque exista una gran brecha entre lo que o el Estado, a través de políticas públicas y legislación dice, ¿qué son los niños? Vivimos en diferentes áreas geográficas de la Amazonía. Las conclusiones del estudio muestran que los niños, así como la exploración de su trabajo que les lleva a una vida digna, a saltar, ir a la escuela, la educación, la salud y un dormitorio de calidad, también subvierten la lógica capitalista y a través de las culturas de sus hijos luchan y resisten la barbarie. del mundo "civilizado".

Palabras-clave: Derechos humanos; trabajo infantil; niños del Amazonas; Paraense Amazon.

\section{ABSTRACT}

The objective of this study is to analyze the logic of predatory capital for a generational group of children, such as riverside, indigenous, caboclas, quilombolas, fishermen, beach workers, peasants, forest peoples, landless, settlers, small farmers, immigrants, colonists and urban subversion this 
capitalist logic. The applied methodology was derived through a qualitative approach, based on bibliographic and documentary research. Based on data that promote or study the centrality of governmental and non-governmental organizations, notably UNICEF, IMAZON, IBGE, ILO, Agência Brasil, Ministry of Women, Family and Human Rights, Ministry of Education, Ministry of Justice / Federal Highway Police, Special Secretariat for Social Security and Labor, with a focus on the Amazon in Paraguay. The main results show that attending to the basic needs of children and the protection and social security policies for their full development even if there is a great gap between what or the State, through public policies and legislation says, what they are kids? We live in different geographical areas of the Amazon. The study's conclusions show that children, as well as the exploration of their work that leads to a dignified life, jumping, going to school, education, health and a quality bedroom, also subvert capitalist logic and through their children's cultures struggle and resist the barbarism of the "civilized" world.

Keywords: Human rights; child labor; children of the Amazon; Paraense Amazon.

[...] todas as crianças trabalham, isto é, desempenham uma actividade social. O paradoxo está em que a condenação da exploração do trabalho infantil tem arrastado consigo a ocultação de formas de trabalho não associadas à exploração e remetido as crianças para o estatuto de seres excluídos da esfera de produção [...] (Sarmento, Bandeira \& Dores, 2002, p. 105).

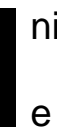
niciamos esse percurso a partir de estudos que mostram que as crianças trabalham e ou sempre trabalharam, que o trabalho faz parte do dia a dia das crianças (Sarmento, Bandeira \& Dores, 2002); isso não chega a ser um problema social quando o trabalho tem um princípio educativo, isto é, aquele "que não as limite de vivenciar outras experiências humanas" (Arenhart, 2007, p. 135), como as brincadeiras, as relações com seus pares, a construção de suas culturas infantis, próprio das infâncias. Para a compreensão de como as crianças têm sido tratadas pelas sociedades contemporâneas capitalistas, este estudo mostra as infâncias amazônicas e seus atores sociais, as crianças, do norte do Brasil: ribeirinhas, indígenas, caboclas, quilombolas, pescadoras, camponesas, praieiras, povos da floresta, sem-terra, 
assentadas, pequenas agricultoras, imigrantes, colonas e urbanas, residentes nos diversos espaços geográficos das tantas Amazônias contrastadas: da várzea e da terra firme, dos rios de águas brancas e águas pretas, dos terrenos movimentados, das planícies litorâneas, dos cerrados, dos manguezais e das florestas (Gonçalves, 2012). Analisamos a partir de dados estatísticos de instituições governamentais e não governamentais o quadro de como elas têm sido vitimadas pelo sistema, sendo o trabalho infantil um dos mecanismos de abuso das infâncias, o qual deixa sequelas irreparáveis para esse grupo geracional.

Mesmo com todas as violências às quais são submetidas, as crianças subvertem a lógica de que pouco ou nada sabem; de fato elas dominam muitos saberes:

conhecem as marés do rio que enche e vaza; conhecem o período apropriado para a coleta dos frutos da floresta; entendem a geografia dos rios e das matas; trazem consigo a cultura de seus antepassados presentes em suas cantigas, danças, lendas e saberes amazônidas (Coelho, Santos \& Silva, 2015, p. 49).

O capital predatório tem como fundamento a exploração econômica com vistas a aumentar a concentração de renda e o fortalecimento das relações assimétricas e de poder, com base na opressão da força de trabalho das populações historicamente excluídas. Nessa lógica, o capital busca utilizar todas as capacidades do sistema neoliberal de regulação para infligir às estratégias de enfrentamento das camadas populares as diferentes formas de opressão, sejam elas socioeconômicas, políticas, culturais, artísticas, religiosas e outras.

Para Frigotto:

No plano do tecido estrutural de um capitalismo que potencializa a memória da colonização, do longo período escravocrata forjando uma classe burguesa predatória e violenta cuja matriz de pensamento é, como mostra Caio Prado, o mimetismo, a cópia, enriquece menos pelo trabalho e mais pelo assalto ao 
fundo público, endividamento externo e pela exponencial exploração do trabalho (2009, p. 74).

As marcas indeléveis do sistema capitalista mostram a negação aos direitos humanos, sobretudo das crianças e suas infâncias na Amazônia, potencializando a herança colonizadora europeia de desumanização e barbárie.

A Constituição Cidadã de 1988, segundo o disposto na alínea II do Art. 4º , estabelece que a República Federativa do Brasil rege-se nas suas relações internacionais pelo princípio da prevalência dos direitos humanos, como bem inalienável à condição humana e uma forma de assegurar às populações brasileiras o direito à vida, à liberdade de opinião e de expressão, o direito ao trabalho e à educação, o direito ao lazer, ao bem-estar social, portanto, o direito a viver com dignidade. Nessa perspectiva capitalista não é possível enxergar o trabalho infantil como princípio educativo, balizador de uma proposta emancipadora frente ao sistema do capital, uma vez que "[...] esse sentido humanizador se perde para dar lugar a outro sentido: a acumulação capitalista" (Arenhart, 2007, p. 136).

Nesse estudo o trabalho é concebido como "[...] condição básica e fundamental de toda a vida humana. E em tal grau, até certo ponto, podemos afirmar que o trabalho criou o próprio homem" (Engels, 2013, p. 13). Nesse sentido Frigotto assevera que,

[...] o trabalho como princípio educativo está vinculado [...] à concepção dos processos sociais e educativos [...] as bases sociais, culturais e científicas das múltiplas dimensões do ser humano no horizonte da práxis revolucionária, para a transição a um novo modo de produção e organização da vida social (2009, p. 71).

Nessa direção Arenhart corrobora:

[...] pelo trabalho o ser humano se humaniza, é por meio dele que os homens e as mulheres se educam, se desenvolvem, criam, inventam, constroem signos e conhecimentos, códigos de identificação cultural, especializam competências, 
sedimentam valores e regras de convivência social que vão diferenciá-los ou identificá-los culturalmente (2007, p. 136).

A dimensão humanizante do trabalho educativo contribui para a produção das condições básicas de sobrevivência e de sociabilidade das infâncias e das crianças da Amazônia. Para Frigotto, Ciavatta \& Ramos "[...] o esforço das forças progressistas deve caminhar no sentido [...], onde se possa pensar o trabalho de modo que o sujeito não seja o mercado e, sim, o mercado seja uma dimensão da realidade social" (2005, p.76).

Esse caráter emancipador é o que caracteriza a subversão das crianças frente à lógica do capital predatório, de vez que elas, de certa maneira, enfrentam a exploração nos diferentes espaços geográficos da Amazônia, transgridem de forma subversiva o monopólio capitalista dos empresários e atravessadores, seja na colheita do açaí, do feijão, na catação do caranguejo, na plantação e produção da farinha de mandioca, na pesca, no corte e retirada da madeira e minérios, entre outras, desacatando as regras impostas socialmente, ao que Arenhart (2007) chama de transgressão.

A transgressão é a saída encontrada pelas crianças para vivenciar essa satisfação do tempo presente. Ao enfrentarem as regras impostas pela lógica capitalista, as crianças estabelecem com outros atores sociais a possibilidade de fazer diferente daquilo que 0 sistema lhes impõe, além de construírem a cultura infantil (Andrade, 2018).

\section{Percurso Metodológico}

A metodologia aplicada se deu por meio de uma abordagem qualitativa, baseada numa pesquisa bibliográfica e documental, realizada em várias fontes que mostram um mosaico da situação das crianças frente ao trabalho infantil na região Norte do Brasil.

Os documentos governamentais analisados são oriundos dos Ministérios, notícias oficiais sobre o trabalho infantil, a saber: a) Ministério da Mulher, da Família e dos 
Direitos Humanos; b) Ministério da Educação; c) Secretaria Especial de Previdência e Trabalho; d) Instituto Brasileiro de Geografia e Estatística - IBGE; e) Agência Brasil; f) Ministério da Justiça - Polícia Rodoviária Federal (PRF).

Para análise dos documentos não governamentais selecionou-se três organizações: a) Organização Internacional do Trabalho (OIT); b) Fundo das Nações Unidas para a Infância (UNICEF); c) Instituto do Homem e Meio Ambiente da Amazônia (IMAZON). Nos documentos das organizações governamentais e não governamentais o foco de análise foi o trabalho infantil. Primeiramente pesquisou-se os documentos em sites oficiais como o Ministério da Mulher, da Família e dos Direitos Humanos com a temática trabalho e família, evidenciando-se nessa relação a lógica do trabalho infantil. No site da PRF, centrou-se especialmente nas ações e programas para o enfretamento do trabalho infantil nas rodovias e estradas federais. No site do Ministério da Educação, centrou-se especialmente nas ações e programas para o enfretamento do trabalho infantil e a permanência do aluno na Educação Básica. Igualmente recorreu-se a Secretaria Especial de Previdência e Trabalho para conhecer como empresas têm desenvolvido ações na área do combate à exploração infantil. Em seguida consultou-se o site do IBGE sobre as estatísticas sociais, econômicas e multidomínio sobre o trabalho, condições de vida, desigualdade e pobreza das crianças. E, ainda, as notícias da Agência Brasil sobre o trabalho infantil. No segundo momento pesquisou-se as organizações não governamentais, como a OIT, a respeito das normas internacionais para o trabalho infantil, os Programas e Projetos no Brasil. Em seguida consultou-se o UNICEF, em específico a evolução dos indicadores e experiências de destaque na promoção dos direitos de crianças e adolescentes, concentrando esforços na vulnerabilidade social, com foco especial em vítimas de formas extremas de violência. E ainda se buscou dados do IMAZON, voltado para promover a conservação e o desenvolvimento sustentável na Amazônia, com foco no direito e sustentabilidade. 
A partir da seleção dos documentos procedeu-se à leitura na íntegra, com destaque parcial ou total para os discursos sobre o trabalho infantil, direitos humanos e a forma perversa do capital predatório na Amazônia.

\section{Capital predatório e trabalho infantil}

No cenário mundial a Amazônia tem sido marcada pela sociobiodiversidade e pelo uso extensivo de recursos naturais cujos efeitos são a geração de áreas degradadas que impactam negativamente a qualidade de vida das crianças e de suas infâncias na Amazônia, diminuem o oferecimento de serviços ecossistêmicos e inviabilizam processos econômicos. O grande desafio que se impõe às sociedades em âmbito mundial é a implementação de uma "[...] restauração ecológica de larga escala, capaz de lidar com a questão climática, a recuperação da biodiversidade, a segurança alimentar, a oferta de água, a qualidade do solo, a geração de energia limpa" (Andrade \& Romeiro, 2009, p. 68) que contribua para a criação de oportunidades de trabalho como princípio educativo e de inclusão social.

Para a OIT o termo "trabalho infantil" é definido como o trabalho que priva as crianças de sua infância, seu potencial e sua dignidade, e que é prejudicial ao seu desenvolvimento físico e mental. A Convenção № 182 da OIT, ratificada pelo Brasil em 2000, tem como prioridade absoluta a eliminação imediata dos trabalhos que prejudicam a saúde, a segurança e a moral da criança, uma vez que os prejuízos interferem diretamente em seu desenvolvimento físico, emocional, social e educacional.

O trabalho infantil tem sido demarcado pela lógica capitalista predatória que afeta a condição das crianças na Amazônia, interferindo no processo de escolarização, na privação de oportunidade de frequência à escola e no prematuro abandona à Educação Básica, ou muitas vezes exige-se a combinação entre a frequência escolar 
e o trabalho excessivo, longo e pesado, que reverbera para a negação dos direitos à vida com dignidade, à liberdade e à democracia.

O capital predatório, antrópico, autodestrutivo e avassalador, produz a concentração e o desmonte dos serviços sociais e de amparo às populações pobres, favorecendo a manutenção das "[...] relações de poder de dominação e dependência existentes em favor dos países subdesenvolvidos, a adoção generalizada da utilização predatória dos limitados recursos de nosso planeta" (Mészáros, 2011, p. 39).

As crianças da Amazônia vivem em contextos sociocultural e econômico diferenciados e são exploradas nas mais diferentes atividades econômicas. Corsaro (2011), referindo-se à exploração do trabalho infantil relaciona-o diretamente à pobreza, ressaltando ainda que a maior parte dos trabalhos realizados pelas crianças é ilícito, o que as torna vulneráveis à exploração das condições de trabalho, horas, salários e normas de segurança, por exemplo.

O trabalho infantil expressa-se como um fenômeno de larga duração histórica e muda no tempo com a proporção da oferta e da demanda, as formas de inserção no mercado, as ocupações e as condições de trabalho.

$\mathrm{Na}$ contemporaneidade o trabalho infantil fortalece os mecanismos de potencialização e transparência exacerbada de deterioração das condições de vida, exposta na miséria de crianças e adolescentes que trabalham em diversas atividades informais na Amazônia, trazendo em sua "[...] esteira uma desigualdade crescente e uma dureza extrema para a avassaladora maioria do povo" (Mészáros, 2011, p. 64).

\section{Direitos humanos e o trabalho infantil na Amazônia}

O trabalho infantil não tem legitimidade e coíbe crianças e adolescentes de desfrutar uma infância em que possam vivenciar experiências que contribuam de maneira positiva para o seu pleno desenvolvimento, é o que enfatiza a OIT ao afirmar: 
O trabalho infantil é ilegal e priva crianças e adolescentes de uma infância normal, impedindo-os não só de frequentar a escola e estudar normalmente, mas também de desenvolver de maneira saudável todas as suas capacidades e habilidades. Antes de tudo, o trabalho infantil é uma grave violação dos direitos humanos e dos direitos e princípios fundamentais no trabalho, representando uma das principais antíteses do trabalho decente (OIT, 2020). Segundo dados da OIT, no Brasil há cerca de 2,7 milhões de crianças e adolescentes em situação de trabalho infantil, deste total 59\% são meninos e $41 \%$ são meninas. Das cinco regiões, o Norte é onde a maior incidência se dá no setor agrícola, as demais concentram-se no setor de serviço e no setor industrial.

Essas formas de exploração acentuaram-se a partir do contexto pandêmico da Covid 19, que mostrou outras faces igualmente perversas do sistema capitalista. 0 ano de 2020 foi difícil para toda a população mundial, pois a pandemia afetou todos os segmentos da sociedade (econômico, social, político, religioso, cultural, lazer, educacional, saúde, entre outros). No Brasil esse quadro se intensificou na medida em que as autoridades demoraram a considerar a doença como uma pandemia e agir de maneira coerente, ágil e com responsabilidade no seu combate, seguindo as determinações e orientações de protocolos da Organização Mundial de Saúde (OMS). Essa morosidade afetou diretamente as comunidades tradicionais e indígenas da Amazônia no que se refere à informação da gravidade da doença, dos cuidados para com a saúde pública, a alimentação, o trabalho, a economia e o próprio convívio social. A este panorama está atrelado o aumento do trabalho infantil, o que pode ocorrer durante e após a pandemia, conforme alerta do UNICEF Brasil. Com o fechamento de empresas, fábricas e de pequenos negócios familiares o desemprego e a fome foram inevitáveis, forçando as crianças e adolescentes a "ajudarem" suas famílias. A esse respeito o UNICEF destaca: 
A pandemia da Covid-19 traz, como efeito secundário, o risco de aumento do trabalho infantil no Brasil. Com as escolas fechadas para prevenir a transmissão do vírus e a pobreza se acentuando, o trabalho pode parecer, equivocadamente, uma forma de meninas e meninos ajudarem suas famílias. Mas ele impacta o desenvolvimento físico e emocional das crianças e pode impedir a continuidade da educação, reproduzindo ciclos de pobreza nas famílias - além de ser porta de entrada para uma série de outras violações de direitos, como a violência sexual (UNICEF, 2020).

Por sua vez, o IMAZON destaca que a Amazônia vive situação de calamidade nos aspectos sociais, ambientais e econômicos. Os dados sobre a situação do trabalho na região mostram uma realidade cruel para as populações amazônidas, sobretudo para crianças e adolescentes, embora as taxas de desemprego tenham diminuído nos últimos dez anos, isso não se traduz em melhorias das condições de vida dos povos da Amazônia, pelo contrário, "[...] essa realidade esconde graves problemas como a informalidade, o trabalho infantil e o trabalho forçado" (IMAZON, 2016).

Ressalte-se também questões fundamentais relacionadas ao trabalho escravo e ao analfabetismo na Amazônia, o que afeta sobremaneira a população infantojuvenil que muitas vezes acompanha seus pais e/ou responsáveis no regime de "ajuda" nas diferentes formas de trabalho, levando as crianças a serem obrigadas a não frequentarem a escola.

Andrade corrobora que a condição de "ajudantes" se constitui como uma das formas de exploração do capital:

Embora chamadas de "ajudantes" - termo que alivia a culpa dos que exploram o trabalho das crianças - para realizarem "pequenas" ações, elas executam tarefas pesadas, como subir em dezenas de árvores para apanhar açaí ou carregar várias caixas de mercadorias a troco de balas e biscoitos (2018, p. 433). 
As atividades exploradoras estão para além da cultura dos círculos domésticos, das relações coletivas e familiares e produzem modos de escravização e de negação dos direitos. O Observatório da Prevenção e da Erradicação do Trabalho Infantil destaca que na região norte do Brasil o trabalho infantil se dá principalmente em atividades agrícolas, diferente das demais regiões. Os dados levantados pelo Observatório dão conta que "[...] o trabalho infantil em meio rural possui particularidades distintas daquele observado em ambientes urbanos" (Observatório da Prevenção e da Erradicação do Trabalho Infantil, 2017).

A histórica exploração da Amazônia sob a orientação capitalista segue ainda hoje a mesma lógica dos colonizadores, assentada na exploração da mão de obra barata e da retirada dos recursos naturais (madeira, ouro, bauxita, manganês, sementes e outros). As tensões e conflitos se tornaram presentes entre os exploradores e a população, transformando nas últimas décadas a Amazônia em um espaço "de devastação, de exploração, de violências e resistência" (Gonçalves, 2012, p. 13). As consequências se mostram também nos outros índices de desenvolvimento social que afetam em muito a vida das crianças e dos jovens (Andrade, 2018).

Lopes (2012, p. 21) aponta dados sociais de pesquisas realizadas na Amazônia que mostram a opressão a que estão submetidas as crianças e os adolescentes: "[...] exploração de crianças por aliciadores, o trabalho infantil, a prostituição infantil [...] crianças expostas a todo tipo de violência, crianças escalpeladas, ausência de educação de qualidade [...]" - esse é o quadro vivido pelos pequenos amazônidas.

A história da Amazônia é também uma história de violência contra as crianças, como podemos observar na exploração do trabalho infantil nas serrarias, na violência sexual intrafamiliar, estupro de crianças e jovens por pessoas próximas (vizinhos, amigos), casamento de meninas com homens bem mais velhos, alienação parental, prostituição e tráfico de menores para o mercado de exploração sexual (Cardozo, 2016). Essa é a 
realidade que precisa ser enfrentada pelo poder público e pela sociedade, é uma luta de todos em prol da infância.

No contexto educacional os dados da Prova Brasil (SAEB), promovida pelo INEP/MEC, de caráter censitário, atingiu todas as escolas públicas brasileiras, sendo que em escolas privadas ela foi amostral. No estado do Pará o tema do trabalho fora de casa foi um dos questionários aplicados; os resultados mostram que alunos do $5^{\circ} \mathrm{e}$ 9o anos do ensino fundamental declararam trabalhar fora de casa, num total correspondente a 28.403 alunos. Nos demais estados da Amazônia Legal também se evidenciou considerável número de crianças e adolescentes que trabalham fora de casa, a saber: Amazonas 14.437, Maranhão 24.627, Tocantins 6.233, Rondônia 5.926, Acre 2.266, Roraima 1.901, Amapá 2.887 e Mato Grosso 10.775 (IBGE, 2017).

Os dados do Censo Agropecuário do IBGE de 2017 trazem informações sobre trabalho infantil de menores de 14 anos de idade em estabelecimentos agropecuários. Esses dados ajudam a refletir sobre a política de prevenção e erradicação do trabalho infantil especialmente em áreas rurais. De acordo com o IBGE esta dimensão ganha relevância estratégica dada o contexto das desigualdades observadas desde 2015, em relação ao aumento da pobreza e da desigualdade no campo e nas florestas (IBGE, 2017). Embora se perceba que houve uma queda nos números do trabalho infantil nos últimos anos, ainda se tem cerca de 292 mil crianças que trabalhavam na produção para consumo da família, como aquelas ocupadas na agricultura de subsistência. $O$ Censo Agropecuário do IBGE destaca que:

Entre as crianças de 5 a 13 anos, predomina o trabalho como auxiliar familiar, ou seja, quando as crianças ajudam outro morador de seu domicílio em alguma atividade econômica sem serem remuneradas por isso [...]. As crianças nessa condição são $73 \%$ das que estão ocupadas em atividades econômicas dentro desse grupo etário. Essa situação puxa o rendimento médio das crianças 
ocupadas nessa idade (com ou sem remuneração) para $R$ \$ 132,00 (IBGE, 2017).

Deste modo, se constata mais uma vez que crianças e adolescentes continuam sendo explorados, em nome da "ajuda" que dão aos adultos. A consequência disto é que colocamos as crianças e os adolescentes na situação de invisíveis, além de classificálos como ser "sem autonomia", portanto, não necessitam de remuneração. Nessa continuidade, Sarmento, Bandeira \& Dores esclarecem que:

[...] para além da "invisibilidade" que é criada em torno das actividades que as crianças efectivamente realizam e do estatuto social da infância [...], uma menorização das crianças, identificadas precisamente por não acederem à condição de autonomia atribuída pelo desempenho de uma actividade socialmente considerada como útil (e, consequentemente, remunerada) (2002, p. 105).

Analisam estes autores em seus estudos que grande parte das crianças nunca admite que tenha um trabalho, que realize com autonomia. Pelo contrário, quem tem o trabalho, ou seja, a remuneração pela atividade realizada, é o elemento da família, o adulto. No entanto, as crianças são, de certa forma, compelidas a ajudá-los, pois que elas ainda não adquiriram a desenvoltura necessária para o desempenho da atividade na sua totalidade, o que faz com que cedo se conscientizem de que sua ajuda tem um limite, porém não há interesse em abrir mão dessa ajuda (Andrade, 2018).

\section{Mecanismos de enfrentamento}

O Projeto da PRF denominado de MAPEAR se mostra como um dos mecanismos de enfrentamento da exploração sexual de crianças e adolescentes nas rodovias e estradas federais. O MAPEAR tem por objetivo fazer o mapeamento dos locais de ocorrências desse tipo de exploração e, em parceria com outros órgãos, resgatar a população infantojuvenil desses espaços. Segundo dados apresentados em dezembro 
de 2020 , "cerca de $60 \%$ dos locais críticos se encontram em áreas urbanas e quase a metade dos vulneráveis estão em postos de combustível às margens de rodovias" (Brasil, 2020a).

O MAPEAR pode ser considerado um projeto exitoso, à medida que assinala os pontos vulneráveis à exploração sexual de crianças e adolescentes em mais de 71.000 quilômetros de rodovias e estradas federais em todo o território brasileiro. No Norte do Brasil o Projeto identificou 435 pontos vulneráveis.

A Instrução Normativa no 146, de 25 de julho de 2018, do Ministério do Trabalho/Secretaria de Inspeção do Trabalho, que dispõe sobre a fiscalização do cumprimento das normas relativas à aprendizagem profissional, destaca em seu art. $2^{\circ}$ que de acordo com a Consolidação das Leis do Trabalho (CLT) "os estabelecimentos de qualquer natureza são obrigados a contratar e matricular aprendizes nos cursos de aprendizagem, no percentual mínimo de cinco e máximo de quinze por cento das funções que exijam formação profissional" (Brasil, 2018). Neste sentido, a Secretaria de Inspeção por meio da Relação Anual de Informações Sociais (RAIS) e do Cadastro Geral de Empregados e Desempregados (CAGED) tem condições de analisar os municípios que cumprem ou não a legislação, abrindo assim um canal de comunicação entre as instituições que desenvolvem ações educativas com adolescentes para que as empresas possam contratar jovens aprendizes.

O Ministério da Mulher, da Família e dos Direitos Humanos considera que o trabalho infantil é um problema de saúde pública mundial, que gera diversas consequências negativas para a saúde das crianças e adolescentes envolvidos, além de influenciar no desempenho escolar, no tempo disponível para o lazer e para o convívio social (Brasil, 2020b, p. 4).

Neste sentido, em 2020 junto com a Secretaria Nacional dos Direitos da Criança e do Adolescente (SNDCA) elaborou um material (cartilha) com a finalidade de "chamar a atenção especialmente para o risco de acidentes que as crianças e adolescentes 
estão expostos, buscando informar e mobilizar toda a sociedade para a importância da erradicação do trabalho infantil" (Brasil, 2020b, p. 4).

Embora alguns mecanismos de enfrentamento do trabalho infantil e suas mazelas estejam estabelecidos pelas instituições governamentais, percebe-se que ainda são ínfimas diante das violações que as crianças e adolescentes sofrem diariamente.

\section{Considerações finais}

O estudo teve por objetivo analisar a lógica do capital predatório para com o grupo geracional infância, e como as crianças ribeirinhas, indígenas, caboclas, quilombolas, pescadoras, praieiras, camponesas, povos da floresta, sem-terra, assentadas, pequenas agricultoras, imigrantes, colonas e urbanas subvertem essa lógica capitalista.

A pesquisa identificou que, embora não sendo objeto desta investigação, mas apareceu no decorrer das análises dos dados, diz respeito à dificuldade de reconhecimento da existência do trabalho infantil, mesmo que esteja visível no cotidiano das pessoas, o que pode de alguma maneira dificultar e ou inibir as denúncias. É comum vermos crianças e adolescentes vendendo guloseimas e objetos no sinal, na rua, nos centros urbanos ou na apanha do açaí, na catação de caranguejo, fazendo farinha, na apanha do milho e do feijão, em situação de trabalho infantil. A impressão que temos é que o trabalho infantil foi naturalizado, portanto, gera dificuldades de identificar a violência a que estão submetidos.

O discurso do sistema capitalista para garantir que o trabalho infantil se afirme como uma política necessária busca no senso comum a afirmação de que "é melhor trabalhar do que roubar, do que matar ou se drogar", como se a exploração da mão de obra não tivesse um preço muito alto a ser pago por elas e gerações futuras. Mas, quando analisamos os dados do desenvolvimento infantil, percebemos o que de fato 
as crianças e adolescentes precisam: brincar, estudar, ter condições básicas para viver com dignidade, se relacionar com seus pares e construir as culturas infantis.

O trabalho infantil é considerado uma "ajuda", portanto, as crianças NÃO estão trabalhando, mas apenas ajudando, o que não fere a natureza moral das pessoas ou grupos que usam esse discurso para explorar os menores. Existe uma cadeia de interesses que cresce em torno do trabalho infantil e todo aquele que distribui e incorpora o lucro do produto disponibilizado no mercado é um aproveitador dessa mão de obra.

As crianças e adolescentes vítimas do trabalho infantil estão vulneráveis a diversos tipos de violência, sendo os mais relatados e perversos os abusos sexuais, 0 aliciamento para o tráfico de drogas e aqueles análogos à escravidão. E nesse contexto são as crianças e os adolescentes negros e pobres que, em maior número, são explorados.

Apesar das violências a que crianças e adolescentes da Amazônia são submetidos, eles buscam maneiras de subverter a lógica do capital predatório ao construírem suas culturas e as culturas infantis que se estabelecem nos brincares, nas relações com seus pares, nos seus modos de vida, no trabalho como princípio educativo, muito bem observado no seio das comunidades tradicionais, na forma como expressam o que gostam ou não na escola, na política, na saúde e na maneira como defendem o espaço amazônico - com garra e luta coletiva.

\section{Referências}

Andrade, D., \& Romeiro, A. R. (2009). Capital natural, serviços ecossistêmicos e sistema econômico: rumo a uma "Economia dos Ecossistemas". Texto para Discussão. IE/UNICAMP, 159(1), 37-61.

Andrade, S. S. (2018). A infância da Amazônia Marajoara: sentidos e significados das práticas culturais no cotidiano das crianças ribeirinhas da Vila do Piriá - 
Curralinho/PA. (Tese de Doutorado. Pontifícia Universidade Católica de Minas Gerais, Belo Horizonte, Minas Gerais, Brasil).

Arenhart, D. (2007). Infância, Educação e MST: quando as crianças ocupam a cena. Chapecó: Argos.

Brasil (1988 outubro 5). Constituição da República Federativa do Brasil. Brasília: $\begin{array}{llll}\text { Congresso } & \text { Nacional. } & \text { Recuperado }\end{array}$ http://www.planalto.gov.br/ccivil_03/constituicao/constituicao.htm

Brasil (2018, julho 25). Instrução Normativa $n^{0}$ 146. Fiscalização do cumprimento das normas relativas à aprendizagem profissional. Diario oficial da união, 146. Recuperado de https://www.in.gov.br/materia//asset_publisher/Kujrw0TZC2Mb/content/id/34730621/do1-2018-07-31instrucao-normativa-n-146-de-25-de-julho-de-201834730599\#: :text=2\%C2\%BA\%20Conforme\%20determina\%200\%20art,fun\%C 3\%A7\%C3\%B5es\%20que\%20exijam\%20forma\%C3\%A7\%C3\%A30\%20profiss ional

Brasil (2020a), Ministério da Justiça. Polícia Rodoviária Federal. PRF lança Mapear 2019/2020 para enfrentamento à ESCA. Recuperado de https://www.gov.br/prf/pt-br/noticias/nacionais/prf-lanca-mapear-2019-2020para-enfrentamento-a-esca

Brasil (2020b). Ministério da Mulher, da Família e Direitos Humanos. Consequências do Trabalho Infantil: os acidentes registrados nos Sistemas de Informação em Saúde. Recuperado de https://www.gov.br/mdh/pt-br/assuntos/noticias/20202/junho/ministerio-lanca-cartilha-sobre-as-consequencias-do-trabalhoinfantil/Trabalhoinfantil_MMFDH.pdf

Cardozo, F. (2016). Moralidades e políticas públicas: agenciamentos em torno de casos de abuso e exploração sexual de crianças e adolescentes no Marajó/PA. (Tese de Doutorado. Universidade Federal de Santa Catarina, Florianópolis, 
Santa Catarina, Brasil). Recuperado de https://repositorio.ufsc.br/ xmlui/bitstream/handle/123456789/167761/339982.pdf?sequence=1\&isallowed $=\mathrm{y}$

Coelho, W. N. B., Santos, R. A., \& Silva, R. M. N. B. (2015). Educação e diversidade na Amazônia. São Paulo: Livraria da Física.

Corsaro, W. A. (2011). Sociologia da infância. Porto Alegre: Artmed.

Engels, F. (2013). Sobre o papel do trabalho na transformação do macaco em homem. Em R. Antunes (Org.), A dialética do trabalho: escritos de Marx e Engels. São Paulo: Expressão Popular.

Frigotto, G. (2009). Teoria e práxis e o antagonismo entre a formação politécnica e as relações sociais capitalistas. Trabalho, Educação e Saúde, 7- suplemento, 6782.

Frigotto, G., Ciavatta, M., \& Ramos, M. (2005). Apolítica de educação profissional no governo Lula: um percurso histórico controvertido. Revista Educação e Sociedade, 26(92), 1087-1113.

Gonçalves, C. W. P. (2012). Amazônia, Amazônias. São Paulo: Contexto.

IBGE. (2017). Censo Agropecuário 2017. Recuperado de https://censos.ibge.gov.br/2012-agencia-de-noticias/noticias/23105-numeroscaem-porem-trabalho-infantil-ainda-e-realidade-nopais.html\#: :text=Na\%20faixa\%20et\%C3\%A1ria\%20mais\%20sens\%C3\%ADve I,Domic\%C3\%ADlios\%20Cont\%C3\%ADnua\%20(PNAD\%20Cont\%C3\%ADnua) IMAZON (2016). Amazônia vive situação drástica nos aspectos sociais, ambientais e econômicos, diz estudo. Recuperado de https://imazon.org.br/imprensa/amazonia-vive-situacao-drastica-nos-aspectossociais-ambientais-e-economicos-diz-estudo/. 
Lopes, A. S. C. (2012). A construção da identidade da infância na Amazônia ribeirinha: Ilha de Cotijuba, Belém-Pará. (Tese de Doutorado. Universidade Federal do Rio Grande do Sul, Porto Alegre, Rio Grande do Sul).

Mészáros, I. (2011). Para além do capital: rumo a uma teoria da transição. São Paulo: Bomtempo.

Observatório da Prevenção e Erradicação do Trabalho Infantil. (2017). Alunos de 5o e 9o ano de escolas públicas que trabalham fora de casa. Recuperado de https://smartlabbr.org/trabalhoinfanti//localidade/0?dimensao=provaBrasil

OIT. (2020).

Trabalho infantil.

Recuperado

de https://www.ilo.org/brasilia/temas/trabalho-infanti/lang--pt/index.htm

Sarmento, M. J., Bandeira, A., \& Dores, R. (2002). Trabalho e lazer no cotidiano das crianças exploradas. Em R. L. Garcia (Org.), Crianças, essas conhecidas tão desconhecidas (pp. 103-124). Rio de Janeiro: DP\&A.

UNICEF. (2020). UNICEF alerta para o risco de aumento do trabalho infantil durante e após a pandemia. Recuperado de https://www.unicef.org/brazil/comunicadosde-imprensa/unicef-alerta-para-o-risco-de-aumento-do-trabalho-infantil-durantee-apos

\section{Declaração do contributo dos autores}

SS e RA contribuíram no desenho e implementação da investigação. SS no levantamento dos dados, análise dos resultados e na escrita do manuscrito. RA trabalhou no levantamento dos dados, análise dos resultados e na escrita do manuscrito. Todos os autores discutiram os resultados e contribuíram para a versão final do manuscrito. 


\section{Editor de sección}

Las editoras de sección de este artículo fueron Magali Reis y Mariela Losso.

ORCID ID: 0000-0001-6741-1638

ORCID ID: 0000-0001-7395-1163

Formato de citación

Andrade, S. \& Amorim dos Santos, R. (2021). Direitos humanos e trabalho infantil na Amazônia: a lógica do capital predatório e a subversão de crianças no norte do Brasil. Psicología, Conocimiento y Sociedad, 11(1), 36-56.

doi: http://dx.doi.org/10.26864/PCS.v11.n1.2 